\title{
Immunohistochemical and Clinicopathological Factors Associated with Axillary Lymph Node Metastasis in Breast Cancer Patients of Northern Pakistan
}

\author{
Muhammad Zubair, Muhammad Tahir Khadim, Hassan Tariq, Salman Ali, \\ Omer Ali Khan, Salma Gul
}

Armed Forces Institute of Pathology, Rawalpindi Pakistan, Pakistan.

\begin{abstract}
Background: Breast cancer is the most common type of tumors in Pakistani women, with axillary lymph node (ALN) positivity reported to be one of the most important prognostic factors. This study shows the distribution of various clinical and pathological variables including age, tumor size, grade, histologic subtype, and hormone receptor status among Pakistani women with and without ALN metastasis. Materials and Methods: A total of 245 cases of primary breast cancer from Northern Pakistan were analyzed in this study. Their clinical, pathological and immunohistochemical parameters, including estrogen receptor (ER), progesterone receptor (PR) and Her-2/Neu status, were extracted from previous histopathological reports and stratified based on the occurrence of ALN metastasis. Results: Occurrence of ALN metastasis was significantly different between older age patients above 50 years and younger age patients age $<50$ years $\left[\chi^{2}(1, \mathrm{~N}=245)=14.6, \mathrm{p}<0.001\right]$. There was an increased number of metastases in large sized tumors $>5 \mathrm{~cm}$ in size $(80 \%, \mathrm{n}=60),\left[\chi^{2}(2, \mathrm{~N}=245)=23.1, \mathrm{p}<0.001\right]$ and tumors with higher nuclear grade III $(78.4 \%, \mathrm{n}=40),\left[\chi^{2}(1, \mathrm{~N}=245)=5.1, \mathrm{p}=0.02\right]$. ALN metastasis was inversely associated with expression of estrogen receptor $\left[\chi^{2}(1, \mathrm{~N}=245)=12.5, \mathrm{p}<0.001\right]$, and progesterone receptor $\left[\chi^{2}(1, \mathrm{~N}=245)=<0.001, \mathrm{p}=0.99\right]$, while it was directly associated with Her-2/Neu expression $\left[\chi^{2}(1, \mathrm{~N}=245)=5.63, \mathrm{p}=0.01\right]$. Conclusion: In Pakistani women, ALN metastasis was significantly associated with older age, tumor size, and high-grade tumors showing Her2/Neu expression and was inversely associated with ER, PR expression in breast tumors.
\end{abstract}

Keywords: Axillary lymph node- estrogen receptor-immunohistochemistry- progesterone receptor- Northern Pakistan

Asian Pac J Cancer Care, 2 (4), 53-57

\section{Introduction}

Breast carcinoma is the most common type of female cancers worldwide. It accounts for $23 \%$ of all cancers occurring in women [1]. Globally 1.4 million new cases of breast cancer are diagnosed every year [2]. The major factors defining the geographical differences in the incidence of breast cancer across the world are race, genetics, cultural factors, and environmental exposures [3].In Pakistan, breast cancer is the most common malignancy in females accounting for $24.4 \%$ of all cancers occurring in females[2]. There is a higher incidence of breast cancer in Pakistani women, compared in Western countries. Out of every nine Pakistani women one suffers
Submission Date: 05/03/2017 Acceptance Date: 08/05/2017

from breast cancer, which is the highest incidence rate for breast cancer in Asia[1]. In a study from Shoukat Khanum Memorial Cancer Hospital, Pakistan, breast cancer accounted for $21.5 \%$ out of all cancers in general population and for $45.9 \%$ of all the cancers in females [4].

A study from Karachi, Pakistan, showed the highest incidence of breast cancer among all of the other Asian countries except for Israel. In particular, cancer data from Karachi for 1995-1997 revealed 53.1\% incidence of breast cancer, compared to $69.1 \%$ incidence in 1998-2002, which is the highest among Asian countries [5]. This might be due to the lack of early screening programs which can detect tumors at an early stage. The reason for increased incidence of breast cancers presenting at advanced stage

Corresponding Author:

Dr. Salma Gul

Armed Forces Institute of Pathology, Rawalpindi Pakistan, Pakistan.

Email: salmagu192@hotmail.com 
is due to lack of awareness about screening programmes and low socioeconomic status as it was shown in a study done in Karachi ( $\mathrm{n}=179)$. Only 46\% females knew about mammography, out of which $73 \%$ belonged to an upper socioeconomic class, $48 \%$ to the middle class and $10 \%$ to lower class socioeconomically [6].

A similar study done at Lahore showed only $4.9 \%$ patients had performed a mammogram for screening purposes. Most females were unaware of signs, symptoms and risk factors of breast cancer [7].

Breast cancers have diverse molecular, pathological and clinical features which can greatly affect prognosis and treatment [8]. Tumors which express estrogen and progesterone receptors show a very good response to hormonal therapy and chemotherapy [9]. ER is expressed in $80-90 \%$ of breast cancers, while PR is expressed in $70-80 \%$ cases [10]. Her-2/Neu overexpression is seen in $20 \%$ of breast cancers $[11,12]$. Therefore breast cancer is better represented by a combined expression of these receptors rather than single receptor status $[13,14]$. Interestingly, studies from Pakistan and India showed an increased incidence of breast cancer with more Estrogen receptor (ER) and Progesterone receptors (PR) negative profiles. It is because most of the cases present at a very advanced stage. Our study asserts the importance of early diagnosis to prevent ALN metastasis.

Axillary lymph node (ALN) status is the most important prognostic factor associated with disease-free survival and overall survival rate for breast cancer. In this study, we described various prognostic subgroups of breast cancer based on their immunohistochemical expression of estrogen receptor, progesterone receptor and Her2/Neu status and their association with ALN metastasis in a group of Northern Pakistani women.

Studies show that cultural variations result in the changed biological behavior of a disease in different patient populations [15]. Such studies on different ethnic groups are more in United States, where it has been done on black, Hispanic, white and other populations [16]. These studies showed different outcomes of breast cancers in different ethnic groups. Such studies are limited in our part of the world. So we are limited to the database of a tertiary care institute to look for different clinical, pathological and immunohistochemical factors which predict ALN metastasis in Pakistani females.

This study is an endeavor to detect various clinical, pathological and immunohistochemical factors which predict regional ALN metastasis in breast cancers in our regional settings. Our case numbers are still meeker in some areas but keeping in view a third world country, cost of most investigations cannot be borne on patients to a large extent. We think the information given in this study will help in understanding the biological and clinical behavior of breast cancer and will help in defining various treatment strategies in breast cancers.

\section{Materials and Methods}

This cross-sectional study was done at Histopathology department of Armed Forces Institute of Pathology,
Rawalpind, Pakistan. Cases with radical mastectomy, modified radical mastectomy, and wide local excisions with axillary lymph node dissection were included in this study. Cases of lumpectomy, Trucut biopsies, and incisional biopsies were excluded from the study. Recurrent tumors, sarcomas, biopsies, and benign lesions were also excluded. All these cases were from the northern part of Pakistan. A total of 245 primary breast carcinomas diagnosed between $20^{\text {th }}$ Jan 2014 to $25^{\text {th }}$ Jul 2016 with available data on clinicopathological parameters, hormone receptors, and Her2/Neu status were examined. These consisted of 210 invasive ductal carcinomas (IDC), 20 invasive lobular carcinomas (ILC), and 5 mixed ductal and lobular carcinomas. Other types included 3 mucinous, 2 tubular, 1 papillary, 3 metaplastic, and 1 medullary carcinomas.

Paraffin-embedded tissue and Hematoxyline and Eosin stained slides were retrieved from the histopathological records and assessed for morphology in detail. Age, histologic grade, histologic type, nuclear grade, size of the tumor, and lymph node status were extracted from existing pathology reports in the records. Grading of the tumor was done using Bloom Richardson grading system [17].

Immunohistochemistry (IHC) was applied to the most representative and well-preserved areas of tissue blocks fixed with $10 \%$ buffered formalin. Results of IHC were evaluated and scored semiquantitatively by two histopathologists [18]. A cutoff value was given for each marker for positive or negative staining. Hormone receptors were taken as positive if at least $1 \%$ of tumor cells showed moderate to strong nuclear staining using Allred scoring system [19].

Her-2/Neu membrane staining was scored as 0 if there was no or faint incomplete staining in $<10 \%$ cells; and 1 , if there were faint incomplete staining in $>10 \%$ cells. Score 3 was taken as positive with complete chicken wire like staining in $>10 \%$ cells $[18,19]$.

Statistical analysis was done using SPSS version 19.0. Descriptive statistics were calculated for both quantitative and qualitative variables. Chi-square test was performed and p-values were calculated respectively. A p-value of less than 0.05 was considered as statistically significant.

\section{Results}

This study included a total of 245 breast cancer cases. The patient's age ranged from 28 to 80 years with a mean age of 49.2 years. Among these $47.3 \%$ $(n=116)$ of patients were younger than 50 years. The prevalence of ALN metastasis was $76 \%$ for patients 50 years and older and $52.6 \%$ for patients younger than 50 years, $\left[\chi^{2}(1, N=245)=14.6, p<0.001\right]$. Similarly, tumors less than $2 \mathrm{~cm}$ in size were associated with lower prevalence of ALN metastasis, of $30.3 \%$ compared to $80 \%$ for larger sized tumors $(>5 \mathrm{~cm})$. Both, age and tumor size were significantly associated with ALN metastasis with p-values less than 0.05 as shown in Table 1 .

Prevalence of ALN metastases was significantly different between grade III tumors and grade I, II tumors. 
Table 1. Association of Axillary Lymph Node Metastasis with Various Clinicopathological Parameters

\begin{tabular}{|c|c|c|c|c|c|}
\hline \multirow[t]{2}{*}{ Clinicopathological parameter } & \multirow{2}{*}{$\begin{array}{c}\text { No of Cases } \\
(n=245)\end{array}$} & \multicolumn{2}{|c|}{ Axillary Lymph node status } & \multirow{2}{*}{$\frac{\text { Chi Square }}{\chi^{2}}$} & \multirow[t]{2}{*}{$\mathrm{p}$-Value } \\
\hline & & Positive & Negative & & \\
\hline \multicolumn{6}{|l|}{ Age of Patients } \\
\hline$<50$ Years & $116(47.3 \%)$ & $61(52.6 \%)$ & $55(47.4 \%)$ & 14.6 & $<0.001$ \\
\hline$\geq 50$ Years & $129(52.7 \%)$ & $98(76 \%)$ & $31(24 \%)$ & & \\
\hline \multicolumn{6}{|l|}{ Size of Tumor } \\
\hline$<2 \mathrm{~cm}$ & $33(13.5 \%)$ & $10(30.3 \%)$ & $23(69.7 \%)$ & 23.1 & $<0.001$ \\
\hline $2-5 \mathrm{~cm}$ & $135(55.1 \%)$ & $89(66 \%)$ & $46(34 \%)$ & & \\
\hline$>5 \mathrm{~cm}$ & $77(31.4 \%)$ & $60(80 \%)$ & $17(20 \%)$ & & \\
\hline \multicolumn{6}{|l|}{ Histologic Grade } \\
\hline Grade I, II & $194(79.2 \%)$ & $119(61.3 \%)$ & $75(38.7 \%)$ & 5.1 & 0.02 \\
\hline Grade III & $51(20.8 \%)$ & $40(78.4 \%)$ & $11(21.6 \%)$ & & \\
\hline \multicolumn{6}{|l|}{ Histologic Type } \\
\hline IDC & $210(85.7 \%)$ & $136(64.8 \%)$ & $74(35.2 \%)$ & & \\
\hline ILC & $20(8.2 \%)$ & $12(60 \%)$ & $8(40 \%)$ & 0.68 & 0.71 \\
\hline Others & $15(6.1 \%)$ & $11(73.3 \%)$ & $4(26.7 \%)$ & & \\
\hline
\end{tabular}

The most common histologic type was invasive ductal carcinoma (IDC), $(85.7 \%, \mathrm{n}=210)$ followed by invasive lobular carcinoma (ILC), $(8.3 \%, \mathrm{n}=20)$. ALN metastasis was more frequent in IDC $(64.8 \%, \mathrm{n}=136)$ as compared to $\operatorname{ILC}(60 \%, \mathrm{n}=12)$.

Hormone receptor expression was associated with lower prevalence of ALN metastasis as compared to hormone receptor negative cases. ALN metastasis was the lowest with an expression of both ER and PR $(60 \%, n=90)$ compared to single receptor positive $(71.4 \%, \mathrm{n}=15)$ and hormone receptor negative $(73.8 \%, \mathrm{n}=48)$ tumors as shown in Figure 1.

Patients with Her2/Neu overexpression showed higher ALN metastasis (78.8\%), as compared to Her2/Neu negative cases (61.1\%), as shown in Figure 2. A total of 57 patients showed no expression of all three receptors (Triple negative tumors). These had a higher prevalence of ALN metastasis $(71.9 \%, \mathrm{n}=41)$ as well as shown in Table 2.

\section{Discussion}

Axillary lymph node metastasis is the most important

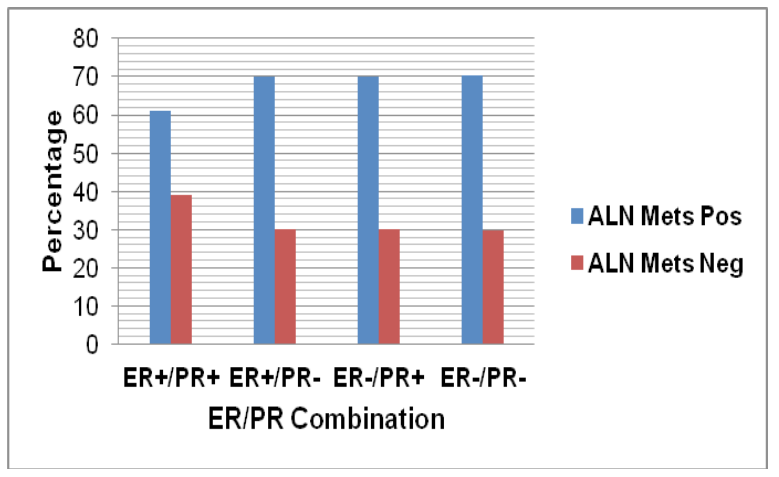

Figure 1. Distribution of Hormone Receptors with ALN Metastasis

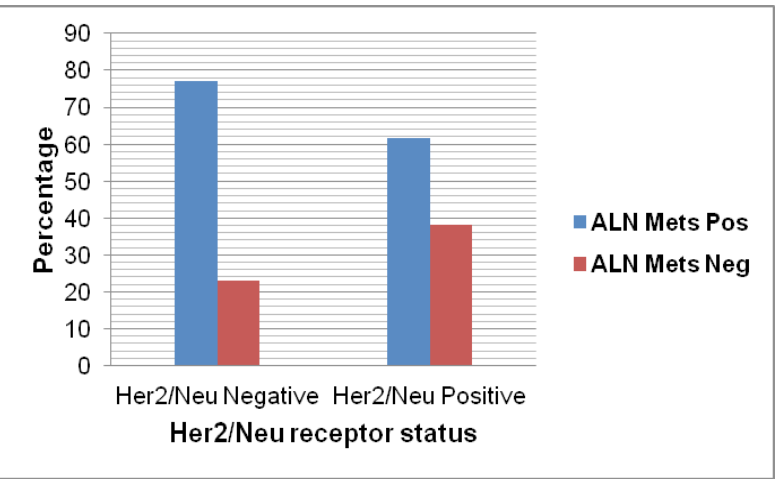

Figure 2. Distribution of Her-2/Neu receptor status with ALN status

prognostic factor for breast cancer patients. Our study showed an association of ALN metastasis with various patient hormone receptor profiles, clinical, and pathological factors. Presence or absence of axillary lymph node metastasis predicts whether a patient will further need adjunct chemotherapy and radiotherapy or not. Also, the number of lymph nodes involvement will help in choosing type and amount of chemotherapy required [20]. This shows the importance of studying various clinical, histopathological and immunohistochemical factors which predict ALN metastasis in breast cancers. These factors are of more importance in patients in whom axillary lymph node dissection is not performed. Thus these factors help to understand the biological behavior of carcinoma breast.

If factors are recognized which have a major effect on ALN metastasis from primary breast cancer, then they can be used as a mean for local treatment planning e.g. In cases where axillary lymph node dissection is not performed or where sentinel lymph node sampling is done [21]. It is especially important when neoadjuvant chemotherapy opts or primary breast cancer is very small. It occurs when mammography is used for screening purpose. 
Table 2. Association of Axillary Lymph Node Metastasis with ER, PR and Her2/Neu Receptor Status

\begin{tabular}{|c|c|c|c|c|c|}
\hline \multirow[t]{2}{*}{ Immunohistochemical parameter } & \multirow{2}{*}{$\begin{array}{c}\text { No of Cases } \\
(n=245)\end{array}$} & \multicolumn{2}{|c|}{ Axillary Lymph node status } & \multirow{2}{*}{$\begin{array}{c}\text { Chi Square } \\
\chi^{2}\end{array}$} & \multirow[t]{2}{*}{ p-Value } \\
\hline & & Positive & Negative & & \\
\hline \multicolumn{6}{|l|}{ Estrogen Receptor } \\
\hline Positive & $164(67 \%)$ & $94(57.3 \%)$ & $70(42.7 \%)$ & 12.5 & $<0.001$ \\
\hline Negative & $81(33 \%)$ & $65(80.2 \%)$ & $16(19.8 \%)$ & & \\
\hline \multicolumn{6}{|l|}{ Progesterone Receptor } \\
\hline Positive & $151(61.6 \%)$ & $98(65 \%)$ & $53(35 \%)$ & $<0.001$ & 0.99 \\
\hline Negative & $94(38.4 \%)$ & $61(64.9 \%)$ & $33(35.1 \%)$ & & \\
\hline \multicolumn{6}{|l|}{ Her-2/Neu Receptor } \\
\hline Positive & $52(21.2 \%)$ & $41(78.8 \%)$ & $11(21.2 \%)$ & 5.63 & 0.01 \\
\hline Negative & $193(78.8 \%)$ & $118(61.1 \%)$ & $75(38.9 \%)$ & & \\
\hline \multicolumn{6}{|l|}{ Subgroups } \\
\hline $\mathrm{ER}+/ \mathrm{PR}+\mathrm{w}$ & $149(60.8 \%)$ & $90(60 \%)$ & $60(40 \%)$ & & \\
\hline $\mathrm{ER}+/ \mathrm{PR}-$ & $21(8.6 \%)$ & $15(71.4 \%)$ & $6(28.6 \%)$ & 4.27 & 0.23 \\
\hline ER-/PR+ & $9(3.7 \%)$ & $6(66.7 \%)$ & $3(33.3 \%)$ & & \\
\hline ER-/PR- & $65(26.9 \%)$ & $48(73.8 \%)$ & $17(26.2 \%)$ & & \\
\hline Total & $245(100 \%)$ & $159(64.9 \%)$ & $86(35.1 \%)$ & & \\
\hline Triple Negative (ER-,PR-,Her-2/Neu-) & $57(100 \%)$ & $41(71.9 \%)$ & $16(28.1 \%)$ & & \\
\hline
\end{tabular}

Factors such as older age, larger tumor size, and grade are associated with higher chances of ALN metastasis compared to younger age, small sized and lowgrade tumors. Similarly, hormone receptor positive and Her $2 / \mathrm{Neu}$ receptor-negative breast cancers were associated with low incidence of ALN metastasis in our population of Northern Pakistan.

Mean age of 49.2 years in this study was in concordance to that reported by Ayadi et al $(n=155)$ [22]. A higher mean age was reported by Onitilo et al $(n=1134)$ [23]. Axillary lymph node metastasis was associated with older age especially above 50 years which was statistically significant with $\mathrm{p}$-value $<0.05$. This finding also signifies the importance of diagnosis of breast cancer at an early age.

The most frequent histologic subtype of breast cancer is Invasive ductal carcinoma accounting for $70-80 \%$ of all invasive breast cancers [24]. Similarly, in our study, IDC was most common $(85.7 \%)$ histologic subtype. This is in similarity to other regional studies by Batool et al $(85 \%)$ [25], Aslam et al (94\%) [26] and Naeem et al (82.6\%) [27] and international studies Ali et al (92\%) as well [28], thus representing the major part of breast cancer cases worldwide.

Larger sized tumors with higher grade were significantly associated with ALN metastasis which was previously shown in Chinese women by Xie et al [29] and Belgian women by Yoshihara et al [30].

We also showed a direct relationship between hormone receptor positivity and Her $2 / \mathrm{Neu}$ receptor expression with ALN metastasis. A total of $78.8 \%$ of Her $2 / \mathrm{Neu}$ positive cases showed ALN metastasis. Conversely, ER and PR positivity were inversely related with the occurrence of ALN metastasis compared to the ER and PR negative cases. This corroborates with previous reports from the USA by Dunnwald et al 2007 and from India by Suvarchala et al 2011 [31, 32]. Some studies show PR+, ER- tumors to be more responsive to hormone therapy but this is not true in all cases [33].

Considering various subgroups of breast cancers based on positivity of ER, PR, and Her2/Neu, ER+, PR+ $\&$ Her-2/Neu - subtype was least associated with ALN metastasis. Triple negative (ER-, PR- \& Her-2/Neu-) breast cancers were associated with the highest incidence of ALN metastasis.

The strength of this study was that it was carried out in an institution which represents most of the population of Northern part of Pakistan. This study will help in providing data for epidemiological interests and it will help in comparing our local data with regional and international research studies. Limitations were that we could not consider other predictive markers for ALN metastasis like molecular and genetic markers due to financial constraints and limited capacity of the laboratory.

Breast cancer is the most important cause of mortality in Pakistani women. Patients usually present very late with a high incidence of axillary lymph node metastasis [7].Such a study was not performed in this area before. We think it will help in the better patient care and incite clinicians and general population for early diagnosis of breast cancers. Further studies should be done in our region to determine the molecular and genetic factors involved in determining ALN metastasis in breast cancers.

\section{References}

1. Asif HM, Sultana S, Akhtar N, Rehman JU, Rehman RU. Prevalence, risk factors and disease knowledge of breast cancer in Pakistan. Asian Pacific journal of cancer prevention: APJCP. 2014;15(11):4411-6.

2. Formenti SC, Arslan AA, Love SM. Global breast cancer: 
the lessons to bring home. International journal of breast cancer. 2011; 2012.

3. Kakarala M, Rozek L, Cote M, Liyanage S, Brenner DE. Breast cancer histology and receptor status characterization in Asian Indian and Pakistani women in the US-a SEER analysis. BMC cancer. 2010; 10(1): 191.

4. Badar F, Faruqui Z, Uddin N, Trevan E. Management of breast lesions by breast physicians in a heavily populated South Asian developing country. Asian Pac J Cancer Prev. 2011;12(3): 827-32.

5. Zubair M, Hashmi SN, Saeed Afzal IM, Din HU, Ahmed R. Immunohistochemical Expression of B Cell Lymphoma-2 with Clinicopathological Correlation in Triple Negative Breast Cancers in Northern Pakistan. Asian Pacific Journal of Cancer Prevention. 2016;17(7): 3619-22.

6. Jaffary A MF, Shamin S, Shamim S. Knowledge, attitudes, and practices regarding breast cancer screening in women of various social strata. J Surg Pak (International). 2005;10:44-

7. Maqsood B, Zeeshan MM, Rehman F, Aslam F, Zafar A, Syed $\mathrm{B}$, et al. Breast cancer screening practices and awareness in women admitted to a tertiary care hospital of Lahore, Pakistan. J Pak Med Assoc. 2009;59(6):418-21.

8. Carey LA, Perou CM, Livasy CA, Dressler LG, Cowan D, Conway K, et al. Race, breast cancer subtypes, and survival in the Carolina Breast Cancer Study. Jama. 2006;295(21): 2492-502.

9. Barnes DM HA. Oestrogen and progesterone receptors in breast cancer: past, present, and future. Histopathology. 2001;3(38): 271-4

10. Grann VR, Troxel AB, Zojwalla NJ, Jacobson JS, Hershman D, Neugut AI. Hormone receptor status and survival in a population-based cohort of patients with breast carcinoma. Cancer. 2005;103(11): 2241-51.

11. Esteva FJ, Hortobagyi GN. Prognostic molecular markers in early breast cancer. Breast cancer research. 2004;6(3):109.

12. Ross JS, Fletcher JA, Linette GP, Stec J, Clark E, Ayers $\mathrm{M}$, et al. The Her-2/neu gene and protein in breast cancer 2003: biomarker and target of therapy. The oncologist. 2003;8(4):307-25.

13. Sørlie T, Perou CM, Tibshirani R, Aas T, Geisler S, Johnsen $\mathrm{H}$, et al. Gene expression patterns of breast carcinomas distinguish tumor subclasses with clinical implications. Proceedings of the National Academy of Sciences. 2001;98(19): 10869-74.

14. Yao Z-x, Lu L-j, Wang R-j, Jin L-b, Liu S-c, Li H-y, et al. Discordance and clinical significance of ER, PR, and HER2 status between primary breast cancer and synchronous axillary lymph node metastasis. Medical oncology. 2014;31(1):798.

15. MD. S. Ethnic variation as a key to the biology of human disease (ed.). Ann Int Med. 1997;5:401 - 3.

16. Edwards MJ GJ, Vaughan WP, et al. Infiltrating ducts! carcinoma of the breast - the survival impact of race. Clin Oncol. 1998;16:2693 - 99

17. Elston CW, Ellis IO. Pathological prognostic factors in breast cancer. I. The value of histological grade in breast cancer: experience from a large study with long-term follows up. Histopathology. 1991;19(5): 403-10.

18. Callagy GM, Pharoah PD, Pinder SE, Hsu FD, Nielsen TO, Ragaz J, et al. Bcl-2 is a prognostic marker in breast cancer independently of the Nottingham Prognostic Index. Clinical Cancer Research. 2006;12(8): 2468-75.

19. Kreike B, van Kouwenhove M, Horlings H, Weigelt B, Peterse H, Bartelink H, et al. Gene expression profiling and histopathological characterization of triple-negative/ basal-like breast carcinomas. Breast Cancer Research. 2007; 9(5): R65.

20. OsbomeKC CG, Ravdin PM. Adjuvant systemic therapy of breast cancer, in diseases of the breast, in: Harris JR. Lippman ME, Morrow M, et a! (eds.). Philadelphia, Lippincott-Raven. 2000: 599- 632.

21. Krag D, Weaver D, Ashikaga T, Moffat F, Klimberg VS, Shriver $C$, et al. The sentinel node in breast cancer-a multicenter validation study. New England Journal of Medicine. 1998; 339(14): 941-6.

22. Ayadi L, Khabir A, Amouri H, Karray S, Dammak A, Guermazi M, et al. Correlation of HER-2 over-expression with clinicopathological parameters in Tunisian breast carcinoma. World Journal of Surgical Oncology. 2008;6(1): 112.

23. Onitilo AA, Engel JM, Greenlee RT, Mukesh BN. Breast cancer subtypes based on ER/PR and Her2 expression: comparison of clinicopathologic features and survival. Clinical medicine \& research. 2009;7 (1-2): 4-13.

24. Li CI UD, Daling JR. Clinical characteristics of different histologic types of breast cancer. Br J Cancer. 2005; 93: 1046-52.

25. Batool M AM, Gardezi J. An experience with breast disease in a surgical unit of a teaching hospital of Lahore. Biomedical. 2005; 21: 108-12.

26. Aslam MN AA, Siddique A, Imran M. Carcinoma breast, late presentation-a big concern. Ann King Edward Med Coll. 2006; 2: 317-9.

27. Naeem M KN, Aman Z, Nasir A, Samad A, Khattak A. Pattern Of Breast Cancer: Experience At Lady Reading Hospital, Peshawar. J Ayub Med Coll Abbottabad 2008;20(4).

28. Ali EM, Ahmed AR, Ali AM. Correlation of breast cancer subtypes based on ER, PR and HER2 expression with axillary lymph node status. Cancer and Oncology Research. 2014;2(4): 51-7.

29. Xie F, Yang H, Wang S, Zhou B, Tong F, Yang D, et al. A logistic regression model for predicting axillary lymph node metastases in early breast carcinoma patients. Sensors. 2012;12(7): 9936-50.

30. Yoshihara E, Smeets A, Laenen A, Reynders A, Soens J, Van Ongeval C, et al. Predictors of axillary lymph node metastases in early breast cancer and their applicability in clinical practice. The Breast. 2013;22(3): 357-61.

31. Dunnwald LK, Rossing MA, Li CI. Hormone receptor status, tumor characteristics, and prognosis: a prospective cohort of breast cancer patients. Breast Cancer Research. 2007;9(1): R6.

32. Suvarchala SB NR. Carcinoma Breast histopathological and hormone receptors correlation. J Bio Sci Tech. 2011(2):340-8

33. Bardou V-J, Arpino G, Elledge RM, Osborne CK, Clark GM. Progesterone receptor status significantly improves outcome prediction over estrogen receptor status alone for adjuvant endocrine therapy in two large breast cancer databases. Journal of Clinical Oncology. 2003;21(10):1973-9.

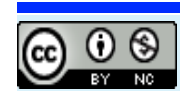

This work is licensed under a Creative Commons AttributionNon Commercial 4.0 International License. 